\title{
Impact of Preoperative Serum Levels of CA 125 on Epithelial Ovarian Cancer Survival
}

\author{
Heru Pradjatmo
}

\begin{abstract}
Background: CA125 is very helpful in treatment monitoring and detection of epithelial ovarian cancer (EOC) recurrence. However there is controversy as to its accuracy and optimal usage. What is the impact of the CA125 levels before primary surgery treatment to the survival of patients? This study aimed to detect any association of preoperative serum levels with prognosis and survival in EOC patients. Materials and Methods: Our cohort comprised EOC patients in Dr. Sardjito Hospital, Yogyakarta, Indonesia, who complied with follow up. To explore the effect of preoperative CA125 levels and other variables on survival Cox's regression models were applied. Results: A total of 90 cases of EOC who had surgery were available for follow up. The level of CA125 proved to be a prognostic factor for overall survival of EOC patients, with an adjusted HR of $4.10(p=0.03)$. Adjuvant chemotherapy was another prognostic factor, 1 - 2 cycles having an adjusted $H R$ of $0.17(p=0.04)$ and 3 - 8 cycles HR $0.39(p=0.06)$. Other factors such as age of patients adjusted HR $1.54(p=0.32)$, moderate differentiation (adjusted HR 1.61, $p=0.51$ ) poor differentiation (adjusted HR 3.41, $p=0.15$ ), and stage of disease (adjusted HR $1.98, p=0.27$ ) were statistically not significant. However, this might have been because the power of the study was low. Conclusions: Preoperative level of $\mathrm{CA125}$ is a prognostic factor for overall survival in EOC patients. The best cut-off for prognostic classification of CA125 serum level is $70 \mathrm{U} / \mathrm{ml}$.
\end{abstract}

Keywords: Preoperative - CA125 - prognosis - survival - epithelial ovarian cancer

Asian Pac J Cancer Prev, 17 (4), 1881-1886

\section{Introduction}

Ovarian cancer is gynecologic cancer as the fourth highest cause of death in women. Ovarian cancer in the United States is still the first cause of gynecologic cancer deaths (Siegel et al. 2015). Despite maximum efforts have been made to develop a new way of screening, diagnosis, and treatment strategies, but the incidence and mortality of ovarian cancer did not change significantly. Ovarian cancer death rate over the past five decades did not decrease significantly compared with other cancers such as cancer of the uterus, stomach, colon and rectum (Jemal et al., 2008). Many factors affect the prognosis of patients with ovarian cancer, such as age, performance status, disease stage, histopathology type, the degree of differentiation, ascites more than $500 \mathrm{ml}$ and residual tumor (du Bois et al., 2009). Ovarian cancer is gynecologic malignancies gave overall the highest risk of death (Colombo et al., 2006; Siegel et al., 2015).

Cancer antigen (CA)125 is a protein in the blood obtained in various conditions including ovarian cancer. A review of 15 studies showed that rising CA125 levels in $50 \%$ of patients with stage I disease, $90 \%$ in stage II, $92 \%$ stage III, $94 \%$ in stage IV disease (Jacobs and Bast,
1989). Although the C125 is a useful tumor marker for monitoring disease progression of ovarian cancer, CA 125 alone is not helpful for a test screening of ovarian cancer. This test is not sensitive enough to diagnose the early stages of the disease. More than $85 \%$ of women with advanced disease occur rising levels of CA125 (> 35 U/ $\mathrm{ml})$. Nearly $6 \%$ of women without ovarian cancer CA125 levels gained more than $35 \mathrm{U} / \mathrm{ml}$ (Urban, 2003).

CA125 is very useful in treatment monitoring and detection of ovarian cancer recurrence. CA125 measurements can be helpful only in women where ovarian cancer has been diagnosed, CA125 as a prognostic marker, not a diagnostic marker for detecting ovarian cancer. It is agreed that CA125 potential as a useful marker for ovarian cancer, although controversy about how accurately these markers to determine the status and how the optimal way to use it. Some studies have suggested that the levels of serum CA125 may be a prognostic factor for survival in ovarian cancer patients. CA125 levels were mostly decreased in patients with ovarian cancer who respond to chemotherapy (Rustin et al., 2009). CA125 levels were very high before the operation was associated with a poor prognosis, and patients with CA125 levels of more than $259 \mathrm{U} / \mathrm{ml}$ before chemotherapy begins has 
a poor prognosis (Parker et al., 1988). But information about CA125 levels after administration of first, second or third chemotherapy is still high indicating the patient has a poor prognosis, so it will affect the consideration of the clinician to stop or change treatment. Several research groups show that the absolute levels of CA125 after first, second or third chemotherapy is a prognosis variable for survival (Redman et al., 1990; Rustin et al., 2009). How do the CA125 levels before primary operations treatment to the survival of patients? Several studies are still obtained controversial results so that still need to be investigated to get more research then a meta-analysis of research will be able to perform and will found the best evidence.

\section{Materials and Methods}

The design was a prospective cohort study, a population study of all patients with ovarian cancer who were treated at the Dr. Sardjito Hospital, Yogyakarta, Indonesia. The research sample was epithelial ovarian cancer (EOC) patients who can be performed following up. Some of the variables examined and recorded, such as CA125 serum levels before surgery, age, weight and height then BMI was calculated and then classified by the classification for Asians people, histopathological type, the degree of differentiation, number of chemotherapy, disease stage, and residual tumor during surgery. The staging of illness classified according to FIGO staging. Each of these variables was grouped into two or three groups. Distribution of variables recorded was presented in Table 1. To explore the effect of preoperative CA125 levels and other variables with the survival of the EOC patients for bivariable and multivariable analysis with Cox's regression models.

\section{Results}

The study obtained 90 cases of epithelial ovarian cancer who had surgery and patients was able to follow up. The shortest followed-up of patients was 18 months, and the longest followed-up was 54 months. None of the patients received chemotherapy before surgery. The distribution of observed variables is presented in Table 1. All patients examined serum CA125 levels before surgery and in the analysis were grouped into two groups, $<70 \mathrm{U} / \mathrm{ml}$ there were $29 / 90(32.2 \%)$ and $\geq 70 \mathrm{U} / \mathrm{ml}$ there

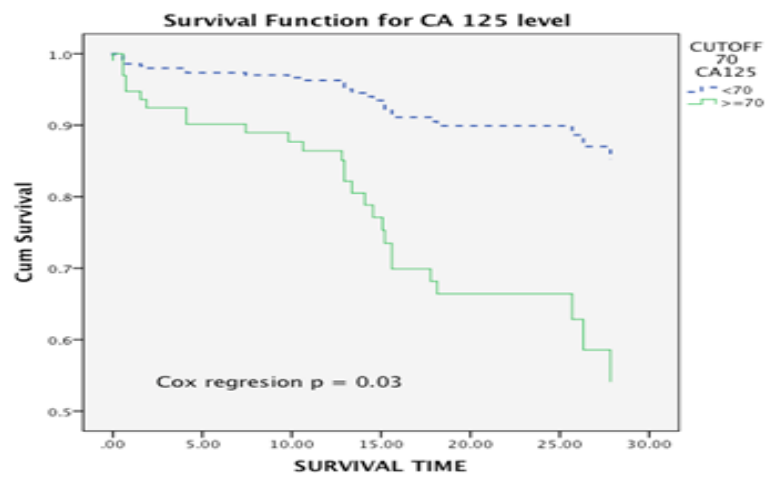

Figure 1. Survival Curve Based on CA125 with 70 U/ ml Cut off Point Classification were $61 / 90(67.8 \%)$. Most patients aged $>50$ years there were $59 / 90(65.6 \%)$. BMI of the patients in the analysis classified into two groups. An underweight to normal there were $65 / 90(65.5 \%)$ and overweight to obese there were $25 / 90$ (34.5\%), histological type were divided into three groups: serous type $25 / 90(27.8 \%)$ mucinous type $44(48.9 \%)$ other types $21 / 90(23.4 \%)$. The degree of differentiation remains classified as usual, well, moderate and poor differentiated. The number of chemotherapy

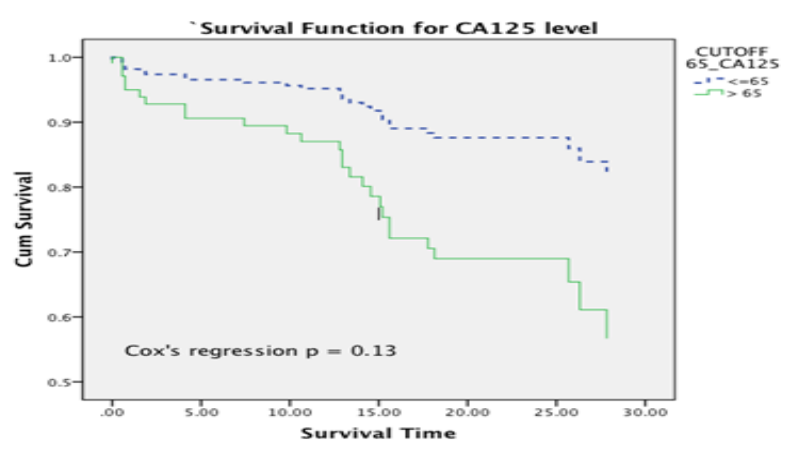

Figure 2. Survival Curve Based on CA125 with 65 U/ ml Cut-off Point Classification

Table 1. Characteristic Distribution of the 90 Cases of Epithelial Ovarian Cancer (EOC)

\begin{tabular}{|c|c|c|}
\hline Variable & No. & $\%$ \\
\hline \multicolumn{3}{|l|}{ CA 125 levels: } \\
\hline$<35 \mathrm{U} / \mathrm{ml}$ & 20 & 22.2 \\
\hline $35-69.9 \mathrm{U} / \mathrm{ml}$ & 9 & 10 \\
\hline$\geq 70 \mathrm{U} / \mathrm{ml}$ & 61 & 67.8 \\
\hline \multicolumn{3}{|l|}{ Age (years): } \\
\hline$<50$ & 59 & 65.6 \\
\hline$\geq 50$ & 31 & 34.4 \\
\hline \multicolumn{3}{|l|}{ BMI (For Asian): } \\
\hline Underweight & 10 & 4.4 \\
\hline Normal & 55 & 61.1 \\
\hline Overweight & 23 & 25.8 \\
\hline Obese & 8 & 8.9 \\
\hline \multicolumn{3}{|l|}{ Histologic type: } \\
\hline Serous & 25 & 27.8 \\
\hline Mucinous & 44 & 48.9 \\
\hline Endometrioid & 5 & 5.6 \\
\hline Clear cell & 14 & 15.6 \\
\hline Undiferentiated & 2 & 2.2 \\
\hline \multicolumn{3}{|l|}{ Grade: } \\
\hline Well differentiated & 44 & 48.9 \\
\hline Moderate differentiated & 20 & 22.2 \\
\hline Poor differentiated & 26 & 28.9 \\
\hline \multicolumn{3}{|l|}{ Chemotherapy: } \\
\hline No chemo & 15 & 16.7 \\
\hline $1-2$ times & 12 & 13.3 \\
\hline $3-8$ times & 63 & 70.0 \\
\hline \multicolumn{3}{|l|}{ FIGO Stage: } \\
\hline I & 26 & 28.9 \\
\hline II & 9 & 10.0 \\
\hline III & 46 & 51.1 \\
\hline IV & 9 & 10.0 \\
\hline \multicolumn{3}{|l|}{ Residual tumor: } \\
\hline Optimal $(<1 \mathrm{ml})$ & 30 & 33.3 \\
\hline Suboptimal ( $1-2 \mathrm{ml})$ & 29 & 32.2 \\
\hline Non optimal $(>2 \mathrm{ml})$ & 31 & 34.5 \\
\hline
\end{tabular}


Table 2. Bivariable and Multivariable Cox's Regression Model Analysis of Patient Characteristics

\begin{tabular}{|c|c|c|c|c|}
\hline \multirow[t]{2}{*}{ Risk factor } & \multicolumn{2}{|c|}{ Bivariable } & \multicolumn{2}{|c|}{ Multivariable } \\
\hline & Crude HR (95\% CI) & $\mathrm{p}$ & Ajusted HR (95\% CI) & $\mathrm{p}$ \\
\hline \multicolumn{5}{|l|}{ CA 125 level: } \\
\hline$<70 \mathrm{U} / \mathrm{ml}$ & 1 & & 1 & \\
\hline$\geq 70 \mathrm{U} / \mathrm{ml}$ & $5.13(1.54-17.10)$ & $<0.01$ & $4.10(1.07-15.76)$ & 0.03 \\
\hline \multicolumn{5}{|l|}{ Age: } \\
\hline$<50$ & 1 & & 1 & \\
\hline$\geq 50$ & $1.59(0.74-3.41)$ & 0.22 & $1.54(0.65-3.63)$ & 0.32 \\
\hline \multicolumn{5}{|l|}{ B M I: } \\
\hline Under+Normal & 1 & & 1 & \\
\hline Overweight & $0.55(0.13-2.36)$ & 0.42 & $0.97(0.40-2.33)$ & 0.94 \\
\hline \multicolumn{5}{|l|}{ Hystological type: } \\
\hline Serous & 1 & & 1 & \\
\hline Mucinous & $1.08(0.40-2.88)$ & 0.87 & $2.18(0.53-8.88)$ & 0.27 \\
\hline Others & $1.55(0.55-4.37)$ & 0.40 & $0.88(0.29-2.64)$ & 0.83 \\
\hline \multicolumn{5}{|l|}{ Grade: } \\
\hline Well diff & 1 & & 1 & \\
\hline Moderate diff & $1.59(0.59-4.28)$ & 0.35 & $1.61(0.38-6.80)$ & 0.51 \\
\hline Poorly diff & $2.22(0.91-5.39)$ & 0.07 & $3.14(0.65-15.43)$ & 0.15 \\
\hline \multicolumn{5}{|l|}{ Chemotherapy: } \\
\hline No chemo & 1 & & 1 & \\
\hline $1-2$ times & $0.36(0.07-1.70)$ & 0.19 & $0.17(0.31-0.95)$ & 0.04 \\
\hline$\geq 3$ times & $0.35(0.15-1.82)$ & 0.01 & $0.39(0.14-1.04)$ & 0.06 \\
\hline \multicolumn{5}{|l|}{ Stage: } \\
\hline $\mathrm{I}+\mathrm{II}$ & 1 & & 1 & \\
\hline III + IV & $3.56(1.34-9.45)$ & 0.01 & $1.98(0.58-6.70)$ & 0.27 \\
\hline \multicolumn{5}{|l|}{ Residu: } \\
\hline Optimal & 1 & & 1 & \\
\hline Non optimal & $1.26(0.55-2.29)$ & 0.57 & $1.03(0.38-2.77)$ & 0.95 \\
\hline
\end{tabular}

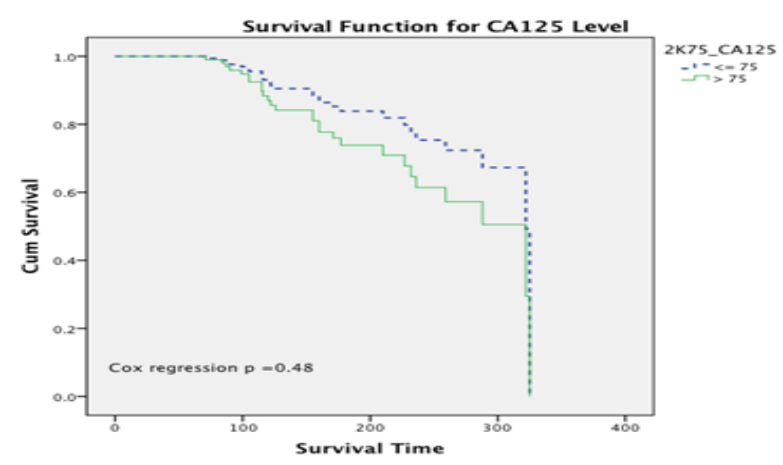

Figure 3. Survival Curve Based on CA125 with 75 U/ ml Cut-off Point Classification

were grouped into three groups as no chemotherapy, 1-2 cycle of chemotherapy and the 3-8 cycle of chemotherapy. Clinical stage divided into two groups, 35/90 (38.9\%) were early stage (stage I and II) and 65/90 (71.1\%) were the advanced stage (stage III and IV). The residual tumor during surgery divided into two groups: the residue $\leq 2$ $\mathrm{ml}$ groups were $59 / 90(65.5 \%)$ and nonoptimal groups $>$ $2 \mathrm{ml}$, were $31 / 90(34.5 \%)$.

\section{Discussion}

Ovarian cancer is rarely found at an early stage as it develops in silent and almost no symptoms. When clinical symptoms are present generally as the result of the growth, development and complications that often arise at the level of an advanced stage. The late stage caused by the absence of specific symptoms and signs at the early stage. By the time symptoms arise ovarian tumor may have grown large enough so that there has been a release of cancer cells into the abdominal cavity. In Pakistan Sarwar et al (2006) reported that 21.2\% EOC patients found in early stage. A previous report in Indonesia ovarian cancer in RSCM Jakarta was obtained early stage ovarian cancer $31.2 \%$ (Sihombing and Sirait, 2007). In the absence of an efficient way for screening of ovarian cancer diagnosis, it is more than $80 \%$ of ovarian cancers are diagnosed at the late stage (Havrilesky et al., 2008). The time when the stage is already advanced cancer will be difficult to cure; then the five years survival will decrease from $95 \%$ in stage I become $20-25 \%$ in the late stage despite the treatment that should be (Rapkiewicz et al., 2004). High risk of mortality mainly caused by cancer has spread to peritoneum or abdominal organs so that treatment may not be optimal.

Some studies suggest that serum CA125 levels may be an important prognostic factor for survival in ovarian cancer patients. CA125 serum levels associated with the tumor, but not all of the increase means the progression of the disease. CA125 is not synthesized only in ovarian cancer cells or ovarian tissue. CA125 may be increased in the state instead of malignancy. Illnesses such as adnexitis, hepatitis, pancreatitis, liver cirrhosis, autoimmune diseases or early pregnancy there is also a rise in CA125. Increased levels of CA125 may also be derived from other epithelial tissues, including pleural coelom, pericardial, as well as epithelial cells of the lung, breast, and even the conjunctiva (Whitehouse and Solomon, 2003). 
Biomarkers for the diagnosis, prognosis, predicts survival and response to therapy are increasingly gaining attention, especially in epithelial ovarian cancer. CA125 is the best-known biomarker for epithelial ovarian cancer and the only biomarker that is still used in everyday practice before other biomarkers acceptable to replace it. Many gynecologist oncologists emphasize the necessity of this biomarker in determining a patient's individual treatment basis (Tingulstad et al., 2003; Hodgall, 2008). It has been agreed that CA125 can not be used as a marker for early diagnosis of ovarian cancer. Only 50\% early stage of ovarian cancers there are increased levels of CA125, and $10 \%$ advanced ovarian cancer levels CA125 is normal (Nustad et al., 1996; Urban, 2003), so that CA125 for ovarian cancer screening the result of positive predictive value is low. It was said that CA 125 can be used for early diagnosis of ovarian cancer in combination with other markers such as VEGF and HE4 (Lawiki et al., 2014). However CA125 will be used as a marker to follow up their recurrence and the results of therapy of epithelial ovarian cancer (Verheijen et al., 1999; Menon \& Jacobs, 2001). Although the benefits of routine examination the levels of CA125 in the followup of patients with ovarian cancer who have achieved a complete response following first-line chemotherapy has not been proven, because the administration of early chemotherapy based on their increased levels of CA125 alone no evidence of survival benefit (Rustin et al., 2010). The role of CA125 levels for the prediction of prognosis survival of ovarian cancer has been reported (Gupta and Lis, 2009), several researchers obtained different results. Researchers reported that preoperative CA125 levels not to be a prognostic factor for survival in ovarian cancer patients were Nassar et al (2015) they used a cut-off 351 $\mathrm{U} / \mathrm{ml}$. Osman et al (2008); Gadducci et al (1995); they used a cut-off CA125 $500 \mathrm{U} / \mathrm{ml}$. Cooper et al (2002) used a cut-off of $160 \mathrm{U} / \mathrm{ml}$ or above, Makar et al (1992), Liu et al (2015) using a cut-off CA125 $150 \mathrm{U} / \mathrm{ml}$. Cruickshank et al (1987) and Sevelda et al (1989) using a cutoff point CA125 $35 \mathrm{U} / \mathrm{ml}$. Others researchers reported that CA125 was a prognostic factor for survival in ovarian cancer patients. Nagele et al (1995), Moebus et al (1988), Petri et al (2006) using a cut-off CA125 $65 \mathrm{U} / \mathrm{ml}$, Tang et al (2012) using a cut-off CA125 $50 \mathrm{U} / \mathrm{ml}$. In which patients with CA125 levels below the cut-off has significantly higher survival compared to patients who had CA125 levels above the cutoff. Knowledgeable preoperative state of ovarian cancer patients with groups that have a good or poor prognosis that the predictions are accurate and crucial for determining treatment strategies.

In this study used a cut-off CA125 $70 \mathrm{U} / \mathrm{ml}$ based on the results of research which state that the cut-off $70 \mathrm{U} /$ $\mathrm{ml}$ of CA125 provides the best prognosis classification (Rustin et al., 2009). They also said that to choose cut-off levels of CA125 for the prognosis classification can be between $35 \mathrm{U} / \mathrm{ml}$ to $90 \mathrm{U} / \mathrm{ml}$. This study used a cut-off CA125 $70 \mathrm{U} / \mathrm{ml}$ found that preoperative serum CA125 levels of patients with epithelial ovarian cancer are prognostic factor of survival in EOC patients. As seen from the results of the bivariable and multivariable analysis with Cox's regression model. The Crude Hazard Ratio
HR 5.13 (95\% CI: 1.54-17.10) with $\mathrm{p}<0.01$ and adjusted HR 4.10 (95\% CI: 1.07-15.76) with p=0:03 (Table 2). In this study also attempted to be analyzed by cut off $65 \mathrm{U} /$ $\mathrm{ml}$ and cut off $75 \mathrm{U} / \mathrm{ml}$. The result found that for cut-off $65 \mathrm{U} / \mathrm{ml}$ crude HR 4,16 (95\% CI: 1.32-13.92) with $\mathrm{p}=0.02$ and adjusted HR 2.81 (95\% CI: 0.73-10.79) with $\mathrm{p}=0.13$. For cut off $75 \mathrm{U} / \mathrm{ml}$ the analysis result were crude HR 5.13 (95\% CI 1.54-17.10) with $\mathrm{p}<0: 01$ and adjusted HR $1.72(95 \%$ CI $0.36-8.07)$ with $\mathrm{p}=0.48$. So with a cut-off $70 \mathrm{U} / \mathrm{ml}$, showed bigger survival differences as well as statistically or visually in the survival curve in Figure 1,2 and three respectively. These results support the statement of Rustin et al (2009) that the cut-off $70 \mathrm{U} / \mathrm{ml}$ provides the best prognostic classification for CA125. Preoperative serum levels of CA125 is a prognostic factor of survival in epithelial ovarian cancer.

The analysis results of the age of the patient obtained in bivariable as well as multivariable analysis showed statistically not significant where $\mathrm{p}>0.05$. However, seem to me it was clinically significant which is crude HR 1.59 with $\mathrm{p}=0.22$ and adjusted HR 1.54 with $\mathrm{p}=0.32$ means that the risk of death for patients age group $\geq 50$ years the likelihood of mortality more than 1.5 times compared to the age group $<50$ years. The result due to the power of this studied is small or the sample size of this studied is not enough to show the differences of age as a prognostic factor significantly. Liu et al (2014) in their study found that ages was not as a prognostic survival in EOC patients. Other investigators have reported that age was a prognostic factor for survival in ovarian cancer patients (Osman et al., 2008; du Bois et al., 2009; Tang et al., 2012; Liu et al., 2014; Nassar et al., 2015).

The nutritional status of patients did not appear to be significantly affected the survival of patients although it seems nutritional status or a higher BMI had a protective effect where the crude and adjusted $\mathrm{HR}<1$, meaning a better nutritional status has an effect of increasing the survival of patients. Results of a meta-analysis of previous studies concluded that BMI at diagnosis can not be a prognostic factor of survival in ovarian cancer patients either (Bae et al. 2014).

The National Cancer Institutes said that the 5-year survival rate for ovarian cancer patients also depends on histopathological type and the degree of differentiation of tumor cells. This study found that mucinous type is a poor prognostic factor for survival of EOC patients with HR 2.18 compared to the serous type, it was clinically significant, although statistically not significant. Previous researchers reported that histological types were a prognostic factor of survival in ovarian cancer (du Bois et al., 2009; Tang et al., 2012; Chen et al., 2013; Liu et al., 2014).

The degree of differentiation appears affected to the survival of patients in which the degree of differentiation is getting worse with the differentiation is getting worse either. Well differentiated as the reference then the moderate differentiated and poor differentiated had the crude HR $1.56(\mathrm{p}=0.35)$ adjusted HR $1.61(\mathrm{p}=0.51)$ and crude HR $2.22(\mathrm{p}=0.07)$ adjusted HR $3.41(\mathrm{p}=0.15)$ respectively, although its was statistically not significant but clinically significant. Previous research found that 
the degree of differentiation is also a prognostic factor for overall survival (Gadducci et al., 1995; du Bois et al., 2009; Liu et al., 2014; Nassar et al., 2015).

Chemotherapy seems to be the only factor that statistically significant as the prognostic factor of survival of EOC in this studied besides CA125 as the variable of interest of the study. The administration of chemotherapy to the patients provide protection where the survival longer than the patient who did not receive chemotherapy as seen in the multivariable analysis the adjusted HR of the patients who got chemotherapy the two groups adjusted HR $0.17(p=0.04)$ and HR $0.39(p=0.06)$. Liu et al (2014) reported in their study found that adjuvant chemotherapy is significant as a prognostic factor for survival in EOC either.

Previous researchers have reported that stage of the disease is a prognostic factor of survival in ovarian cancer patients (du Bois et al., 2009; Tang et al., 2012; Liu et al., 2014; Chen et al., 2015; Nassar et al., 2015; Pradjatmo, 2015). Becomes more evident that the early diagnosis of ovarian cancer will reduce the mortality. This study found the stage of disease clinically significant as a prognostic factor of survival in EOC patients with crude HR 3.56 $(\mathrm{p}=0.01)$ and adjusted HR $1.98(\mathrm{p}=0.27)$.

This study found that the residual tumor when surgery was not a prognostic factor for patient survival, the analysis obtained crude $\mathrm{HR}=1.27(\mathrm{p}=0.57)$ adjusted $\mathrm{HR}=1.03(\mathrm{p}=0.95)$, even though with nonoptimal surgery the risk of death of EOC patients increase. Other investigators have reported that the residual tumor is a prognostic factor for survival in ovarian cancer patients where if surgery is not optimal survival is lower (Gadducci et al., 1995; Tingulstad et al., 2003; Osman et al., 2008; du Bois et al., 2009; Pongsanon et al., 2011; Liu et al., 2014).

Summary: The study obtained 90 cases of EOC, who had surgery and patients was able to follow up. The variable of interest was the preoperative level of CA125, and the cut-off for prognostic classification is $70 \mathrm{U} / \mathrm{ml}$; the result found that level of CA125 is a prognostic factor for overall survival of EOC patients, the adjusted HR $4.10(\mathrm{p}=0.03)$. The role of CA125 levels for the prediction of prognosis survival of ovarian cancer has been reported. However, several researchers obtained different results. Adjuvant chemotherapy was a prognostic factor either, patients who got chemotherapy $1-2$ cycles adjusted HR $0.17(\mathrm{p}=0.04)$ and who got 3-8 cycles HR $0.39(\mathrm{p}=0.06)$. Other factors such as; age of patients adjusted HR $1.54(\mathrm{p}=0.32)$, grade of differentiation for moderate differentiated adjusted HR $1.61(\mathrm{p}=0.51)$ for poor differentiated adjusted HR 3.41 $(\mathrm{p}=0.15)$, stage of disease adjusted HR $1.98(\mathrm{p}=0.27)$. They were statistically not significant, however, seem to me clinically significant because the power of this study is low or the sample size was not enough to show the significant difference in those factors.

\section{References}

Alvarez RD, To A, Boots LR, et al (1987). CA125 assay serum marker for poor prognosis in ovarian malignancies. Gynecol Oncol, 26, 284-9

Bae HS, Kim HJ, Hong JH, et al (2014). Obesity and epithelial ovarian cancer survival: a systematic review and metaanalysis. J Ovarian Res, 7, 41

Buller RE (2002). Preoperative CA125 levels: an independent prognostic factor for epithelial ovarian cancer. Obstet Gynecol, 100, 59-64

Chen Y, Zhang L, Liu WX, Xiang-Yu Liu XY (2015). Prognostic significance of preoperative anemia, leukocytosis and thrombocytosis in chinese women with epithelial ovarian cancer. Asian Pac J Cancer Prev, 16, 933-9

Chen X, Zhang J, Cheng W, et al (2013). CA-125 Level as a Prognostic Indicator in Type I and Type II Epithelial Ovarian Cancer. Inter J Gynecol Cancer, 23, 815-22

Colombo N, Van GT, Parma G, et al (2006). Ovarian cancer. Crit Rev Oncol Hematol, 60, 159-79

Cooper BC, Sood AK, Davis CS, et al (2002). Preoperative CA 125 levels: an independent prognostic factor for epithelial ovarian cancer. Obstet Gynecol, 100, 59-64.

Cruickshank DJ, Fullerton WT, Klopper A (1987). The clinical significance of pre-operative serum CA125 in ovarian cancer. Br J Obstet Gynaecol, 94, 692-5

du Bois A, Reuss A, Pujade-Lauraine E, et al (2009). Role of surgical outcome as prognostic factor in advanced epithelial ovarian cancer: a combined exploratory analysis of 3 prospectively randomized phase 3 multicenter trials. Cancer, 115, 1234-44

Gadducci A, Zola P, Landoni F, Maggino T (1995). Serum halflife of CA125 during early chemotherapy as an independent prognostic variable for patients with advanced epithelial ovarian cancer: results of a multicentric Italian study. Gynecol Oncol, 58, 42-7

Gupta D, Lis CG (2009). Role of CA125 in predicting ovarian cancer survival-a review of the epidemiological literature. J Ovarian Res, 2, 13

Havrilesky LJ, Whitehead CM, Rubatt JM, et al (2008). Evaluation of biomarker panels for early stage ovarian cancer detection and monitoring for disease recurrence. Gynecol Oncol, 110, 374-82

Hogdall E (2008). Cancer antigen 125 and prognosis. Curr Opin Obstet Gynaecol, 20, 4-8

Jacobs I, Bast RC (1989). The CA125 tumour-associated antigen: a review of the literature. Hum Reprod, 4, 1-12

Jemal A, Siegel R, Ward E, et al (2008). Cancer Statistics, 2008. CA Cancer J Clin, 58, 71-96

Lawiki S, Będkowska GE, Gacuta-Szumarska E, Szmitkowski M (2014). The plasma concentration of VEGF, HE4 and CA125 as a new biomarkers panel in different stages and subtypes of epithelial ovarian tumors. J Ovar Res, 6, 45

Liu XH, Ya-Nan Man YN, Wu XZ (2014). Recurrence season impacts the survival of epithelial ovarian cancer patients. Asian Pac J Cancer Prev, 15, 1627-32

Makar AP, Kristensen GB, Kaern J, et al (1992). Prognostic value of pre and postoperative serum CA125 levels in ovarian cancer: new aspects and multivariate analysis. Obstet Gynecol, 79, $1002-10$

Menon U, Jacobs IJ (2001). Ovarian cancer screening in the general population. Curr Opin Obstet Gynecol, 13, 61-4

Moebus V (1988). Evaluation of CA125 as a prognostic and predictive factor in ovarian cancer. J Tumor Marker Oncol, 3, 251-8.

Nagele F, Petru E, Medl M, et al (1995). Preoperative CA125: an independent prognostic factor in patients with stage I epithelial ovarian cancer. Obstet Gynecol, 86, 259-64

Nustad K, Bast RC Jr, Brien TJ, et al (1996). Specificity and affinity of 26 monoclonal antibodies against the CA 125 antigen: first report from the ISOBM TD-1 workshop. international society for oncodevelopmental biology and medicine. Tumour Biol, 17, 196-219 
Osman N, O'Leary N, Mulcahy E, et al (2008). Correlation of serum CA125 with stage, grade and survival of patients with epithelial ovarian cancer at a single centre. Ir Med J, 101, 245-7

Parker D, Patel K, Alred EJ, et al (1988). CA125 and survival in ovarian cancer. J Royal Soc Med, 82, 22.

Petri AL, Hogdall E, Christensen IJ, et al (2006): Preoperative CA125 as a prognostic factor in stage I epithelial ovarian cancer. APMIS, 114, 359-63

Pradjatmo H (2015). Methylation status and expression of brca2 in epithelial ovarian cancers in indonesia. Asian Pac J Cancer Prev, 16, 8599-604

Pongsanon K, Benjapibal M, Ruengkhachorn I (2011). Prognostic significance of hemoglobin levels in patients with primary epithelial ovarian carcinoma undergoing platinumbased chemotherapy. Asian Pac J Cancer Prev, 12, 131-6

Rapkiewicz AV, Espina V, Petricoin EF, Liotta LA (2004). Biomarkers of ovarian tumours. Eur J Cancer, 40, 2604-12

Redman CWE, Blackledge GR, Kelly K, et al (1990). Early CA125 response and outcome in epithelial ovarian cancer. Eur J Cancer, 26, 593-6

Rustin GJ, van der Burg ME (2009). A randomized trial in ovarian cancer (OC) of early treatment of relapse based on CA125 level alone versus delayed treatment based on conventional clinical indicators (MRC OV05/EORTC 55955 trials). J Clin Oncol, 27, 1

Rustin G, van der Burg M, Griffin C, et al (2010). Early versus delayed treatment of relapsed ovarian cancer (MRC OV05/ EORTC 55955): a randomized trial. Lancet, 376, 1155-63

Sarwar SCM, Siddiqui N, Khokhar RA, Badar F (2006) Epithelial ovarian cancer at a cancer hospital in a developing country. Asian Pac J Cancer Prev, 7, 595-8

Sevelda P, Schemper M, Spona J (1989). CA125 as an independent prognostic factor for survival in patients with epithelial ovarian cancer. Am J Obstet Gynaecol, 161, 1213-6.

Siegel RL, Miller KD, Jemal A, (2015). Cancer statistics, 2015. CA Cancer J Clin, 65, 5-29

Sihombing M, Sirait AM (2007). Angka ketahanan hidup penderita kanker ovarium di RS Dr. Ciptomangunkusumo, Jakarta. Maj Kedok Indon, 57, 346-52

Tang A, Kondalsamy-Chennakesavan S, Ngan H, et al (2012). Prognostic value of elevated preoperative serum CA125 in ovarian tumors of low malignant potential: A multinational collaborative study (ANZGOG0801). Gynecol Oncol, 126, 36-40

Tingulstad S, Skjeldestad FE, Halvorsen TB, Hagen B (2003). Survival and prognostic factors in patients with ovarian cancer. Obstet Gynecol, 101, 885-91

Urban N (2003). Specific keynote: Ovarian cancer risk assessment and the potential for early detection. Gynecol Oncol, 88, 75-9

Verheijen RH, Mensdorff-Pouilly S, van Kamp GJ, Kenemans P (1999). CA125: fundamental and clinical aspects. Semin Cancer Biol, 9, 117-24

Whitehouse C, Solomon E (2003). Current status of the molecular characterization of the ovarian cancer antigen CA125 and implications for its use in the clinical setting. Gynecol Oncol, 88, 152-7 